\title{
Effects of sand burial depth on Xanthium spinosum seed germination and seedling growth
}

Yuan-yuan Tao ${ }^{1,2}$, Tian-cui Shang ${ }^{2}$, Jun-jie Yan², Yun-xia Hu², Yu Zhao ${ }^{1,2^{*}}$ and Ying Liu 1, $^{2 *}$

\begin{abstract}
In desert habitats, sand burial is an important factor affecting germination of plant seeds and seedling growth. Xanthium spinosum has strong adaptability in arid desert areas, and is a common malignant invasive plant in Xinjiang, China. The effects of different sand burial depths on seed germination, seedling emergence, growth and biomass allocation were studied to provide a scientific basis for further control of $X$. spinosum. Six sand burial depths $(1,2,3$, 5,7 and $9 \mathrm{~cm}$ ) were established to explore the response of $X$. spinosum seed germination and seedling growth to sand burial. The first emergence time, peak emergence time, emergence rate, seedling growth height, biomass and biomass distribution of $X$. spinosum seeds was significantly different at sand burial depths $(P<0.05)$. The $X$. spinosum seeds had the highest emergence rate $(71.5 \%)$ at $1 \mathrm{~cm}$ sand burial and the maximum seedling height $(7.1 \mathrm{~cm})$. As sand burial depth increased, the emergence rate and seedling height gradually decreased. Emergence rate (12.25\%) and seedling height $(2.9 \mathrm{~cm})$ were lowest at $9 \mathrm{~cm}$ sand burial. The root length at $9 \mathrm{~cm}$ depth $(13.6 \mathrm{~cm})$ was significantly higher than that at other sand depths $(P<0.05)$. The sand burial depth affected the biomass accumulation and distribution of $X$. spinosum. As sand burial depth increased, the root biomass and rhizome ratio increased, and the most deeply buried seedlings allocated more biomass for root growth. The optimal sand burial depth for seed germination and seedling growth of $X$. spinosum was $1-3 \mathrm{~cm}$, and high burial depth $(5-9 \mathrm{~cm})$ was not conducive to the germination and growth of $X$. spinosum seedlings. For prevention and control of $X$. spinosum, we suggest deeply ploughing crops before sowing to ensure $X$. spinosum seeds are ploughed into a deep soil layer.
\end{abstract}

Keywords: Xanthium spinosum, Sand burial, Germination, Seedling growth, Biomass

\section{Background}

In the life cycle of higher plants, the process of seed germination and seedling establishment is the most vulnerable stage for settlement and population establishment; comprises the period of highest sensitivity to habitat conditions; and affects the population number, regeneration rate and community composition [21]. Seed germination is controlled by a mixture of its own internal factors and

\footnotetext{
*Correspondence: zhaoyuliuying@126.com; zylyzhlily@126.com

2 Biology and Geography Science School, Yili Normal University, Yining 835000, China
}

Full list of author information is available at the end of the article environmental factors [6]. The internal factors include seed quality, seed coat thickness, appendages and structure of the seed surface [23], while environmental factors include soil moisture, temperature, light, soil $\mathrm{CO}_{2}$ concentration and sowing or burial depth $[3,6,29,30]$. In arid desert areas, because of the strong wind-sand interaction, sand burial is often the primary factor affecting germination [7]. It also affects plant reproduction and biomass allocation, and can even lead to plant death [10, $18,23]$.

In desert habitats, different sand burial depths can produce selective pressures on seed germination and seedling morphology [26]. When the seeds are buried 
in shallow sand, they are subjected to lower temperature compared with that outside the soil, suitable light conditions, and a humid environment [11, 17, 29], which stimulate germination and growth. When the seed is buried too deep in the sand, the air permeability of the soil is reduced and the light is weakened, thereby inhibiting seed germination and seedling emergence $[4,8,19]$. Therefore, in-depth study of the impact of sand burial on plant seed emergence and seedling growth in desert areas has important theoretical and practical significance.

Among the Asteraceae plants, Xanthium spinosum (spiny cocklebur) is an herbaceous annual weed, a malignant weed that spreads widely in the world but is most widely distributed in Central and Southern Europe and the Pacific Northwest $[2,9]$. In China, X. spinosum was first discovered in Dancheng County, Henan Province, and is now widely distributed in eastern Henan, northwest Anhui, Fengtai District in Beijing, Dalian in Liaoning, Hohhot in Inner Mongolia and Zhongwei in Ningxia [27]. In 2006, X. spinosum was first discovered in the Ili River Valley in Xinjiang, China [5]. Because the surface of the involucre is barbed, it is easily dispersed by people unintentionally, or spread on the fur of animals, and thus can invade a large area in a short time. As $X$. spinosum can adapt to the desert habitat in Xinjiang, China, a large area of invasive populations has formed in the Takermohuer Desert in the Yili River Valley, and the weed has rapidly invaded the oasis, grassland and villages surrounding the desert.

$X$. spinosum has strong adaptability in the desert, and often forms mono-dominant community. At the end of each growing season, a large number of mature involucres form a seed bank, which provides a continuous seed source for community succession, malignant expansion and invasion of sandy habitats, and further aggravates the invasion of the surrounding environment. At present, research on $X$. spinosum has mainly focused on the separation and identification of its active components, allelopathy of secondary metabolites, invasion and distribution, and interspecific competition [25]. To our knowledge, no studies have considered the influence of sand burial on the output, settlement, population establishment and community succession of the $X$. spinosum seed bank. Furthermore there has been no consideration of the influence of sand burial on seed germination, seedling growth and morphogenesis of $X$. spinosum. Therefore, this study examined the effects of different sand burial depths on $X$. spinosum seed germination, seedling emergence, growth and biomass allocation in the Yili River Valley. Based on experiments with different sand burial depths, this study aims to (1) determine whether different sand burial depths have any influence on the growth of $X$. spinosum seedlings; (2) explore how different sand burial depths affect the biomass distribution pattern of $X$. spinosum; and (3) reveal the relationship between seedling emergence, growth and sand burial depth, as well as examine the ecological adaptability of seed germination and seedling growth to sand burial.

\section{Results}

\section{Effects of different sand burial depths on the emergence process of $X$. spinosum seeds}

Different sand burial depths have substantial effects on the initial emergence time of $X$. spinosum and the peak time of emergence. At a sand depth of $1 \mathrm{~cm}$, the initial emergence time was shortest at about 5 days, whereas at $9 \mathrm{~cm}$ sand burial depth, the time required for seedlings to be unearthed was longest at about 22 days. In the 3-9 cm treatment group, the deeper the sand burial depth, the longer the time needed for seedling emergence.

The emergence peak time was about 1-2 days after the first emergence time, and had a value of 1 day after the first emergence time when the sand burial depth was 1 $\mathrm{cm}$, whereas the other treatment groups reached the emergence peak after 2 days (Table 1 ).

Figure 1 shows that the emergence rate of $X$. spinosum seeds decreased with the increase of sand burial depth. The emergence rate was fastest at $1 \mathrm{~cm}$ sand burial depth, with values of $14.5 \%$ and $62 \%$ on the 5 days and 10 days after sowing, respectively, and reached $68 \%$ after sowing for 20 days. Subsequently, the emergence rate only increased slowly, with the highest emergence rate value of $71.5 \%$. The emergence of seedlings was slowest at $9 \mathrm{~cm}$ depth, and they emerged for the first time at 22 days after sowing, with an emergence rate of only $4.75 \%$, and maximum of only $12.25 \%$. The emergence rate of $7 \mathrm{~cm}$ depth was $3.75 \%$ at 11 days and $17.15 \%$ at 13 days, and the highest emergence rate was only $44.25 \%$. There was no significant difference between the emergence rates of $1,2,3$ and $5 \mathrm{~cm}$ after 20 days.

Table 1 Effect of sand burial depth on the emergence process of $X$. spinosum seeds

\begin{tabular}{lll}
\hline $\begin{array}{l}\text { Sand burial depth } \\
\text { (cm) }\end{array}$ & $\begin{array}{l}\text { Seeding emergence } \\
\text { initiation time (d) }\end{array}$ & $\begin{array}{l}\text { Seeding } \\
\text { emergence peak } \\
\text { time (d) }\end{array}$ \\
\hline 1 & $5 \pm 0.05 \mathrm{~d}$ & $6 \pm 0.10 \mathrm{~d}$ \\
2 & $8 \pm 0.13 \mathrm{ab}$ & $10 \pm 0.47 \mathrm{ab}$ \\
3 & $6 \pm 0.15 \mathrm{c}$ & $8 \pm 0.14 \mathrm{c}$ \\
5 & $8 \pm 0.22 \mathrm{~b}$ & $10 \pm 0.52 \mathrm{~b}$ \\
7 & $11 \pm 0.55 \mathrm{a}$ & $13 \pm 0.22 \mathrm{a}$ \\
9 & $22 \pm 0.51 \mathrm{a}$ & $22 \pm 0.00 \mathrm{a}$ \\
\hline
\end{tabular}

The values were represented as means $\pm \mathrm{SE}$. Different lowercase letters indicate significant differences among the different sand burial depths of $X$. spinosum by using one-way ANOVA from LSD tests $(P<0.05)$ 


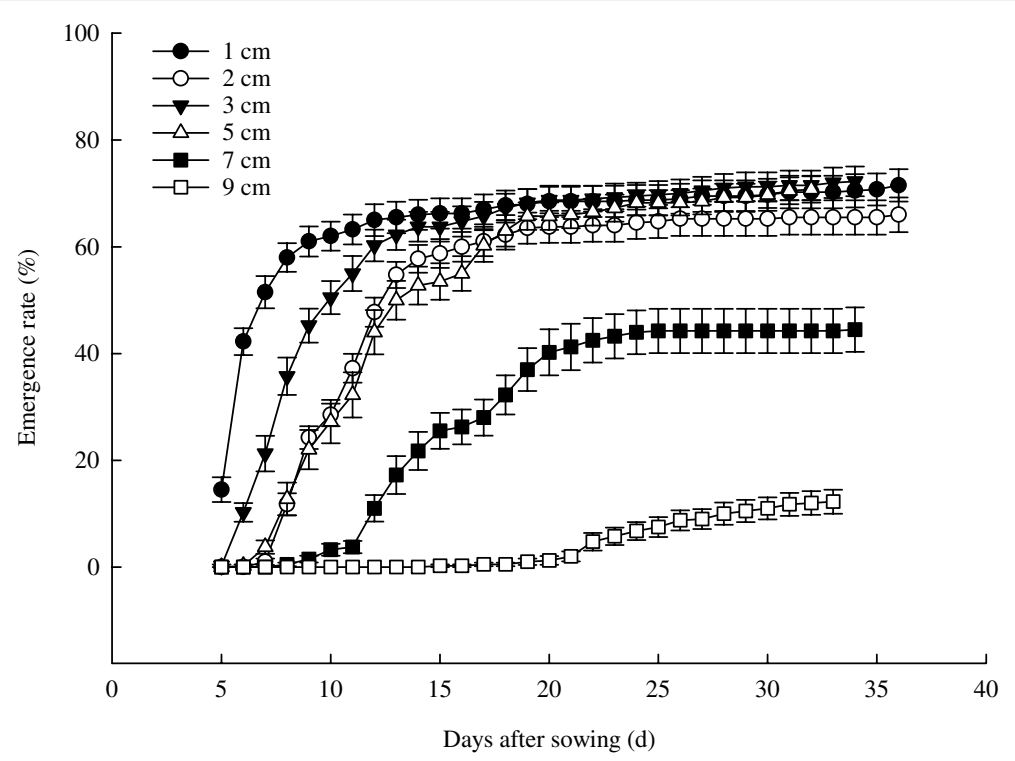

Fig. 1 Effects of different sand burial depths on the emergence process of $X$. spinosum seeds. (The values were represented as means \pm SE)

Relationship between seedling height and sowing days at different sand burial depths

Figure 2 shows that the seedling height of $X$. spinosum was substantially affected by different sand burial depth. As sand burial depth increased, the seedling height gradually decreased. The seedling height at 1-cm burial depth was significantly higher than that at other sand burial depths $(P<0.05)$. From the 15 th day, the seed height under 1-, 2-,3-,5- and 7-cm sand burial depth began to change significantly, and continued to the end of the experimental period. Compared with 1-, 2-,3- and 5-cm sand burial depth, the depth of $7 \mathrm{~cm}$ and $9 \mathrm{~cm}$ were significantly inhibited within 10-20 days after sowing. The heights at burial depths of 7 and

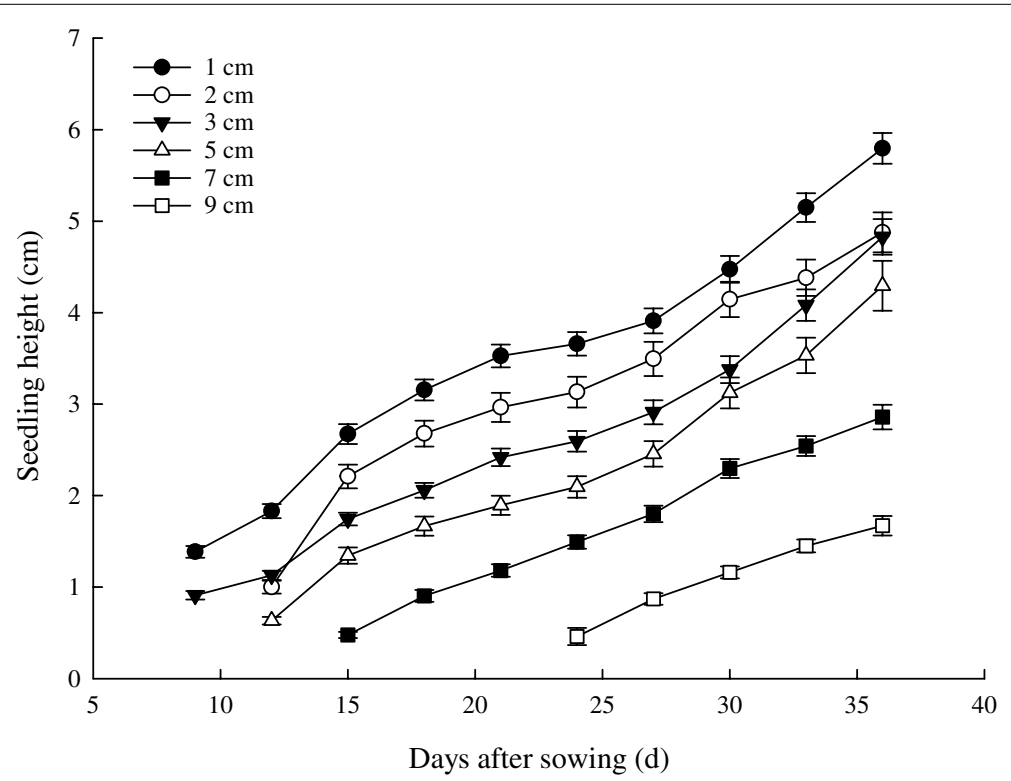

Fig. 2 Relationship between seedling height and sowing days of X. spinosum at different sand burial depths. (The values were represented as means \pm SE) 

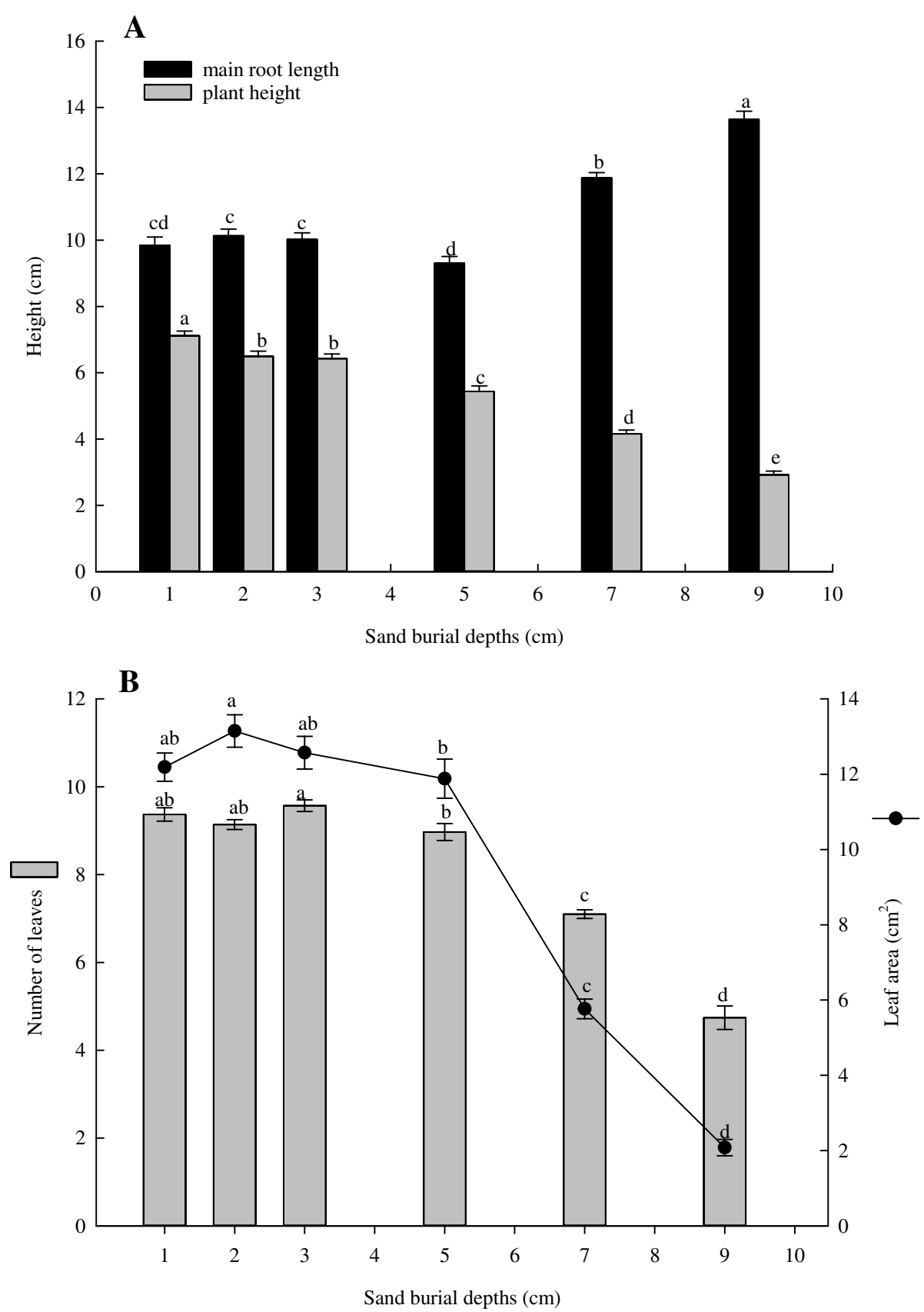

Fig. 3 Morphological characteristics of X. spinosum seedlings at different sand burial depths. (A Main root length and plant height of $X$. spinosum at different sand burial depths; $\mathbf{B}$ The number of leaves and leaf area of $X$. spinosum at different sand burial depths). Different lowercase letters indicate significant differences among the different sand burial depths of $X$. spinosum by using one-way ANOVA from LSD tests $(P<0.05)$. The values were represented as means \pm SE

$9 \mathrm{~cm}$ were not recorded until 15 and 24 days after sowing, respectively. At the end of the experiment, 36 days after sowing, the height of seedlings at $1 \mathrm{~cm}$ sand burial depth was the highest at $5.8 \mathrm{~cm}$, and the height of seedlings at $9 \mathrm{~cm}$ sand burial depth was the lowest at $1.67 \mathrm{~cm}$.

\section{Morphological characteristics of $X$. spinosum seedlings} at different sand burial depths

Figure $3 \mathrm{~A}$ shows that the main root length and plant height were significantly affected by sand burial depth (main root length, $F=48.5, P<0.001$; plant height, $F$ $=105.5, P<0.001$, respectively). The length of the main 
root at 9-cm burial depth was significantly higher than that in other treatment groups $(P<0.001)$, at $13.6 \mathrm{~m}$, and the minimum length of main root in at $5 \mathrm{~cm}$ sand burial depth was $9.3 \mathrm{~cm}$. There was no significant difference in root length at sand burial depths of 1,2 and $3 \mathrm{~cm}(P>$ $0.05)$, with an average value of $10.0 \mathrm{~cm}$ for these depths.

As sand burial depth increased, plant height gradually decreased (Fig. 3A). At 1-cm sand burial depth, the plant height was significantly higher than that of other treatment groups $(P=0.002)$, at $7.1 \mathrm{~cm}$, and the minimum plant height at $9 \mathrm{~cm}$ was $2.9 \mathrm{~cm}$. There was no significant difference in plant height between 2- and 3-cm sand burial depth $(P=0.749)$.

The number of leaves and leaf area was also significantly affected by sand burial depth (number of leaves, $F$ $=97.4, P<0.001$; leaf area, $F=103.7, P<0.001$, respectively) (Fig. 3B). There was no significant difference in leaf number and leaf area at 1-, 2- and 3-cm sand burial depth $(P>0.05)$, but they were significantly higher than those at 5-, 7- and 9-cm sand burial depth $(P<0.05)$. From $5 \mathrm{~cm}$, the number and area of leaves decreased with sand burial depth. At $5 \mathrm{~cm}$ sand burial depth, the number of leaves per $X$. spinosum seedling was about 9 , and the leaf area was $11.8 \mathrm{~cm}^{2}$, but at $9-\mathrm{cm}$ depth, the number of leaves per $X$. spinosum seedling was only about 5 , and the leaf area was only $2.1 \mathrm{~cm}^{2}$.

\section{Biomass accumulation of $X$. spinosum seedlings at different sand burial depths}

The biomass accumulation of $X$. spinosum seedlings was significantly affected by sand burial depth (root biomass, $F=81.0, P<0.001$; stem biomass, $F=95.8, P<0.001$; leaf biomass, $F=92.2, P<0.001$; reproductive component, $F=3.4, P=0.005$; total biomass, $F=63.0, P<$ 0.001 , respectively) (Table 2 ). With the increase of sand burial depth, the root biomass gradually increased, and the root biomass at 9-cm sand burial depth was significantly higher than that at other sand burial depths ( $P$ $<0.001)$ at $0.2854 \mathrm{~g}$, which is about twice of the root biomass at 1-cm sand burial depth. There was no significant difference between the root biomass at 1- and 2-cm sand burial depth $(P=0.698)$, there was significant difference between the root biomass at 2- and 3-cm burial $\operatorname{depth}(P=0.006)$, and there was no significant difference between the root biomass at 5 - and 7-cm burial depth $(P$ $=0.816$ ).

As sand burial depth increased, the stem biomass gradually decreased. The stem biomass at $1-\mathrm{cm}$ burial depth was significantly higher than that at other sand burial depths $(P<0.001)$, at $0.1849 \mathrm{~g}$, which was about 4.5 times the stem biomass at $9-\mathrm{cm}$ sand burial depth $(0.0408 \mathrm{~g})$.

As sand burial depth increased, the leaf biomass showed a decreasing trend. The leaf biomass $(0.6109 \mathrm{~g})$ at $1-\mathrm{cm}$ sand burial depth was significantly higher than that at 9 -cm sand burial depth $(0.1097 \mathrm{~g})(P<0.001)$. There was no significant difference in leaf biomass at sand burial depths of 1-, 2-, 3- and 5-cm $(P>0.05)$.

There was no significant difference among reproductive components at sand burial depths of 1-, 2-, 3- and 5 -cm $(P>0.05)$. At 9 -cm sand burial depth, there was no reproductive component.

The total biomass and leaf biomass both showed an overall decreasing trend with sand burial depth. The total biomass $(0.9933 \mathrm{~g})$ at $1-\mathrm{cm}$ sand burial depth was significantly higher than that at 9-cm sand burial depth $(0.4359$ g) $(P<0.001)$, which was about twice as high. There was no significant difference in total biomass at 2-, 3- and 5 -cm sand burial depths $(P>0.05)$.

\section{Biomass distribution of $X$. spinosum seedlings at different sand burial depths}

The biomass allocation of $X$. spinosum seedlings was significantly affected by sand burial depth (root biomass ratio, $F=387.4, P<0.001$; stem biomass ratio, $F=60.7$, $P<0.001$; leaf biomass ratio, $F=160.1, P<0.001$; root to shoot ratio, $F=91.6, P<0.001$, respectively) (Table 3 ). With the increase of sand burial depth, the root biomass ratio gradually increased, and the root biomass ratio at

Table 2 Biomass accumulation of $X$. spinosum seedlings at different sand burial depths

\begin{tabular}{llllll}
\hline $\begin{array}{l}\text { Different } \\
\text { depths }(\mathbf{c m})\end{array}$ & $\begin{array}{l}\text { Root biomass } \\
\mathbf{( g )}\end{array}$ & $\begin{array}{l}\text { Stem biomass } \\
(\mathbf{g})\end{array}$ & $\begin{array}{l}\text { Leaf biomass } \\
\mathbf{( g )}\end{array}$ & Reproductive component(g) & $\begin{array}{l}\text { Total biomass } \\
(\mathbf{g})\end{array}$ \\
\hline 1 & $0.1329 \pm 0.0047 \mathrm{~d}$ & $0.1849 \pm 0.0055 \mathrm{a}$ & $0.6109 \pm 0.0185 \mathrm{a}$ & $0.0336 \pm 0.0021 \mathrm{a}$ & $0.9933 \pm 0.0258 \mathrm{a}$ \\
2 & $0.1360 \pm 0.0049 \mathrm{~d}$ & $0.1545 \pm 0.0058 \mathrm{~b}$ & $0.5341 \pm 0.0190 \mathrm{~b}$ & $0.0374 \pm 0.0090 \mathrm{a}$ & $0.8855 \pm 0.0300 \mathrm{~b}$ \\
3 & $0.1608 \pm 0.0047 \mathrm{c}$ & $0.1411 \pm 0.0055 \mathrm{bc}$ & $0.5817 \pm 0.0202 \mathrm{ab}$ & $0.0345 \pm 0.0017 \mathrm{a}$ & $0.9459 \pm 0.0293 \mathrm{ab}$ \\
5 & $0.2041 \pm 0.0050 \mathrm{~b}$ & $0.1326 \pm 0.0068 \mathrm{c}$ & $0.5338 \pm 0.0275 \mathrm{~b}$ & $0.0390 \pm 0.0055 \mathrm{a}$ & $0.9363 \pm 0.0379 \mathrm{ab}$ \\
7 & $0.2060 \pm 0.0063 \mathrm{~b}$ & $0.0625 \pm 0.0027 \mathrm{~d}$ & $0.2483 \pm 0.0103 \mathrm{c}$ & $0.0173 \pm 0.0057 \mathrm{~b}$ & $0.5213 \pm 0.0168 \mathrm{c}$ \\
9 & $0.2854 \pm 0.0110 \mathrm{a}$ & $0.0408 \pm 0.0028 \mathrm{e}$ & $0.1097 \pm 0.0121 \mathrm{~d}$ & $0.0000 \pm 0.0000 \mathrm{c}$ & $0.4359 \pm 0.0185 \mathrm{c}$ \\
\hline
\end{tabular}

The values were represented as means \pm SE Different lowercase letters indicate significant differences among the different sand burial depths of $X$. spinosum by using one-way ANOVA from LSD tests $(P<0.05)$ 
Table 3 Biomass distribution of $X$. spinosum seedlings at different sand burial depths

\begin{tabular}{lllll}
\hline $\begin{array}{l}\text { Sand burial } \\
\text { depth }(\mathbf{c m})\end{array}$ & Root biomass ratio & Stem biomass ratio & Leaf biomass ratio & Root to shoot ratio \\
\hline 1 & $0.1359 \pm 0.0046 \mathrm{e}$ & $0.1881 \pm 0.0044 \mathrm{a}$ & $0.6115 \pm 0.0078 \mathrm{a}$ & $0.1600 \pm 0.0069 \mathrm{c}$ \\
2 & $0.1572 \pm 0.0050 \mathrm{de}$ & $0.1764 \pm 0.0051 \mathrm{~b}$ & $0.6022 \pm 0.0095 \mathrm{a}$ & $0.1896 \pm 0.0076 \mathrm{c}$ \\
3 & $0.1754 \pm 0.0048 \mathrm{~d}$ & $0.1493 \pm 0.0031 \mathrm{~cd}$ & $0.6106 \pm 0.0062 \mathrm{a}$ & $0.2160 \pm 0.0073 \mathrm{c}$ \\
5 & $0.2336 \pm 0.0073 \mathrm{c}$ & $0.1406 \pm 0.0048 \mathrm{~d}$ & $0.5553 \pm 0.0110 \mathrm{~b}$ & $0.3142 \pm 0.0133 \mathrm{c}$ \\
7 & $0.4033 \pm 0.0101 \mathrm{~b}$ & $0.1195 \pm 0.0031 \mathrm{e}$ & $0.4693 \pm 0.0082 \mathrm{c}$ & $0.7113 \pm 0.0313 \mathrm{~b}$ \\
9 & $0.6753 \pm 0.0251 \mathrm{a}$ & $0.0918 \pm 0.0051 \mathrm{f}$ & $0.2329 \pm 0.0212 \mathrm{~d}$ & $3.1712 \pm 0.3780 \mathrm{a}$ \\
\hline
\end{tabular}

The values were represented as means \pm SE. Different lowercase letters indicate significant differences among the different sand burial depths of $X$. spinosum by using one-way ANOVA from LSD tests $(P<0.05)$

9-cm sand burial depth was significantly higher than that at other sand burial depths $(P<0.05)$. However, as sand burial depth increased, the stem biomass decreased gradually, and the stem biomass at $1 \mathrm{~cm}$ sand burial depth was significantly higher than that at other sand burial depths $(P<0.05)$. As sand burial depth increased, the leaf biomass ratio showed a decreasing trend. The biomass ratio of leaves at 1-, 2- and 3-cm sand burial depth was significantly higher than that at $9-\mathrm{cm}$ sand burial depth $(P$ $<0.05)$. The root to shoot ratio increased gradually with the increase of sand burial depth, among which the root to shoot ratio at 9-cm sand burial depth was significantly higher than that at other burial depths $(P<0.05)$, and there was no significant difference between root to shoot ratios at 1-, 2-, 3- and 5-cm sand burial depth $(P>0.05)$.

\section{Discussion}

Seed germination and seedling growth are affected by many environmental factors such as habitat disturbance. Sand burial at different depths change the temperature, moisture and light conditions around the seeds, subsequently affecting seed germination and seedling growth $[6,16,28,30]$. Sand burial can adjust the emergence time of seeds [24], and can maintain high humidity, thus preventing the seeds directly exposed to the soil surface from being damaged at high temperature or low temperature, increasing the seedling growth speed. The results of the current study showed that sand burial depth had significant effects on the first emergence time, peak emergence time, emergence rate, seedling growth height, biomass and biomass distribution of $X$. spinosum seeds.

As sand burial depth increased, the emergence rate and seedling height gradually decreased. These results are consistent with those of Maun and Riach [12] and Chen et al. [4] It may be that shallow sand burial can protect seeds from the fluctuation of the external environment, and maintain a suitable and stable light, temperature and humid environment for seed germination and seedling growth $[1,13]$. In addition, shallow sand burial is more conducive to the rejuvenation of seeds, increasing seed germination rate and seedling emergence speed [20]. In contrast, the deep sand burial environment lacks oxygen, light and warmth, and thus the seed germination activity is reduced [15], and seedling growth is inhibited.

The morphological characteristics of $X$. spinosum seedlings at different depths show that the plant height, the number of leaves and leaf area decreases with the deepening of sand burial depth. In contrast, the root length increases with sand burial depth. This was mainly because under shallow sand, more resources are used for the growth of aboveground parts to ensure normal photosynthesis, but with the increase of sand burial depth, the proportion of resources allocated by seedlings to the aboveground parts decreased. If the seed is buried too deep in the sand, the air permeability of the soil is decreased and the light is weakened, thereby inhibiting seed germination and seedling emergence, while although after germination, the seedlings are inhibited by the exhaustion of energy before unearthing [8], and thus do not continue to grow or even die.

The accumulation and distribution of biomass strongly reflect the growth and development of plants. Different sand burial depths affect the rhizome allocation pattern of seedlings. Research focusing on Nitraria sphaerocarpa by Seiwa et al. [14] and Anabasis aphylla by Wang et al. [23] showed that with the increase of depth, the proportion of seedlings allocated to stems will gradually increase, whereas the ratio of roots and stems decrease as burial depth increases. However, in the current experiment, the root to shoot ratio gradually increased as sand burial depth increased. This is mainly because the storage in the seeds is the only source of energy, and the nutrients and energy stored in the seeds are limited, so the seedlings consume the nutrients stored in the seeds when they are unearthed. Therefore, when buried in deep sand, the seedlings allocate more biomass for root growth, which can quickly absorb the water in the deep soil and promote the growth of the aboveground parts. This result 
is consistent with Wang et al. [22], Zuo et al. [30] and Zhu et al. [29], who indicated that the biomass allocation trends of different species have different responses to sand burial through their long-term ecological adaptation, and may be related to the unique adaptability of plants to their living environment. Different material collection sites and soil characteristics will also cause changes in physiological and ecological characteristics of plants, resulting in variations in results.

In summary, $X$. spinosum germinated at $1-9 \mathrm{~cm}$ sand burial depth, but the emergence speed was fastest and the emergence rate was highest at $1-\mathrm{cm}$ sand burial depth. As sand burial depth increased, the emergence rate gradually decreased. Sand burial depth affects the biomass allocation of $X$. spinosum. As sand burial depth increased, root to shoot ratio increased with the increase of depth, and seedlings allocate more biomass for root growth. Therefore, shallow sand burial is beneficial to the emergence of $X$. spinosum seeds, the growth and morphogenesis of seedlings, and the invasion and spread of this plant in arid areas, whereas deep burial is not conducive to $X$. spinosum invasion. Under the current environmental conditions, it is extremely urgent to strengthen the ecological management of $X$. spinosum. Therefore, suggestions for the prevention and control of $X$. spinosum invasion are as follows. The findings of this study indicate that deep ploughing would be beneficial before sowing crops to ensure that the seeds of $X$. spinosum in the soil are ploughed into deep soil. The results of this study will provide the basis for further study on population reproduction and diffusion mechanism, and the further assessment of prevention, control of $X$. spinosum.

\section{Methods and materials}

Plant seeds were collected in the field and did not need to a collection license, because they are invasive plants and invasive weeds with a wide range of growth. In order to ensure the availability of seeds, they were collected uniformly and identified as $X$. spinosum after screening by teachers. Yu Zhao formally identified the samples.

\section{Experimental material}

The seeds of $X$. spinosum were collected from Huocheng County, Ili Kazak Autonomous Prefecture, Xinjiang in mid-October, 2018. This area belongs to a temperate continental semi-arid climate, with a mild climate, four distinct seasons and abundant sunshine.

A wild $X$. spinosum was selected, and mature involucres (brown, usually containing two seeds) were collected at the end of the $X$. spinosum growth period in October. They were brought to the laboratory, sorted to ensure the full involucre was retained, air-dried naturally for a week and stored in the fridge at $4^{\circ} \mathrm{C}$ for later use. Before the experiment, the uniform and full involucre seeds were selected, disinfected with $2.0 \% \mathrm{NaClO}$ sodium hypochlorite solution for $10 \mathrm{~min}$, washed with distilled water three times and then soaked with distilled water for $48 \mathrm{~h}$ in order to accelerate germination.

\section{Research methods}

The involucres were sown after the seed soaking treatment. The sand from desert was placed in a perforated pot with double filter paper, and paved. The pot size was $21 \mathrm{~cm} \times 15 \mathrm{~cm} \times 18 \mathrm{~cm}$, and the bottom sand was $9,8,7,5,3$ and $1 \mathrm{~cm}$. Twenty seeds were placed in each pot and then covered with fine river sand with thickness of 1, 2, 3, 5, 7 and $9 \mathrm{~cm}$ to obtain the different sand burial treatments. Each treatment group was included 10 pots, and the experiment was repeated three times. The pots were covered with plastic film to prevent evaporation of water in surface river sand. After planting, the pots were placed in an incubator, with temperature set at $28^{\circ} \mathrm{C}$ during the day $(14 \mathrm{~h}$ of illumination at $12000 \mathrm{LX})$ and $15^{\circ} \mathrm{C}$ at night $(10 \mathrm{~h})$. The experiment began in June, 2019, and the emergence was recorded from the surface layer of germ-exposed soil. The emergence number was recorded and marked every day, and three seedlings with the same emergence time and height were selected, and others were removed. The nutrient solution (0.5 times MS medium (Table 4) dissolved in 1 liter of water) was added once every 5 days, $200 \mathrm{~mL}$ per basin, and the plant height of the seedlings was measured the next day. The experimental period was 36 days.

Table 4 MS medium composition and concentration

\begin{tabular}{lll}
\hline & Components & $\begin{array}{l}\text { Concentration } \\
\text { (mg. } \mathbf{L}^{-1} \text { ) }\end{array}$ \\
\hline A large number of elements & $\mathrm{KNO}_{3}$ & 1900 \\
& $\mathrm{NH}_{4} \mathrm{NO}_{3}$ & 1650 \\
& $\mathrm{MgSO}_{4} \cdot 7 \mathrm{H}_{2} \mathrm{O}$ & 370 \\
& $\mathrm{KH}_{2} \mathrm{PO}_{4}$ & 170 \\
& $\mathrm{CaCl}_{2} \cdot 2 \mathrm{H}_{2} \mathrm{O}$ & 440 \\
& $\mathrm{Na}_{2} \cdot \mathrm{EDTA}$ & 37.25 \\
Iron salt & $\mathrm{FeSO}_{4} \cdot 7 \mathrm{H}_{2} \mathrm{O}$ & 27.85 \\
& $\mathrm{MnSO}_{4} \cdot 4 \mathrm{H}_{2} \mathrm{O}$ & 22.30 \\
Trace elements. & $\mathrm{ZnSO}_{4} \cdot 7 \mathrm{H}_{2} \mathrm{O}$ & 8.6 \\
& $\mathrm{H}_{3} \mathrm{BO}_{3}$ & 6.2 \\
& $\mathrm{Kl}$ & 0.83 \\
& $\mathrm{Na}_{2} \mathrm{MoO}_{4} \cdot 2 \mathrm{H}_{2} \mathrm{O}$ & 0.25 \\
& $\mathrm{CuSO}_{4} \cdot 5 \mathrm{H}_{2} \mathrm{O}$ & 0.025 \\
$\mathrm{CoCl}_{2} \cdot 6 \mathrm{H}_{2} \mathrm{O}$ & 0.025
\end{tabular}




\section{Index determination}

The initial emergence time was taken as the date when the germ first emerged from the soil surface after sand burial. The peak time of emergence was taken as the date when the number of seeds emerging was the highest after sand burial.

After sampling, the plant height and root length of seedlings were measured with a ruler, and the fresh weights of roots, stems, leaves and reproductive components (inflorescence and involucre)were weighed with an electronic balance. They were then naturally air-dried for one week, and dry weight was recorded.

Characteristics included main root length $(\mathrm{cm})$, plant height $(\mathrm{cm})$, leaf number, root biomass $(\mathrm{g})$, stem biomass (g), leaf biomass (g) and reproductive components (g) recorded.

The calculated indexes include total biomass (sum of all biomass), root biomass ratio (root weight/total weight), stem biomass ratio (stem weight/total weight), leaf biomass ratio (leaf weight/total weight) and root to shoot ratio (underground biomass/aboveground biomass).

\section{Statistical methods}

SPSS 19.0 (SPSS, Chicago, IL, USA) was used to collate the experimental data and conduct data statistics and analysis. Based on normal distribution of data, one-way ANOVA was used to determine the effects of burial depth on seed germination, and seedling growth. The least significant difference (LSD) method was used for multiple comparisons $(P<0.05)$, and SigmaPlot 14.0 (Systat Software Inc., San Jose, CA) was used to generate figures.

\section{Acknowledgments}

We thank my younger junior for their assistance during plant cultivation and harvesting. We are grateful to the Fay Editor providing valuable comments.

\section{Authors' contributions \\ Conceptualization, methodology and validation, Y. Z. and Y. L.; Formal analysis, investigation, resources and data curation, T. S. and Y.H.; Writing-original draft preparation, Y.T.; Writing-review \& editing, Y. Z.\&Y. L.; Project administration, Y. Z.; Funding acquisition, Y. Z.\&Y. L. All authors have read and approved the manuscript.}

\section{Funding}

This work was supported by the National Natural Science Foundation of China (Grant Nos. 31660144 and 31460764) and the Natural Science Foundation of Xinjiang Uygur Autonomous Region, China (Grant No. 2016D01C388).

\section{Availability of data and materials}

The datasets generated and/or analysed during the current study are not publicly available due the data is still being supplemented and improved, and it needs to be reflected in the graduation thesis in the later stage, but are available from the corresponding author on reasonable request.

\section{Declarations}

Ethics approval and consent to participate

Not applicable

\section{Consent for publication}

Yes

\section{Competing interests}

The authors declare that they have no competing interests

\section{Author details}

${ }^{1}$ History, Geography and Tourism School, Shangrao Normal University, Shangrao 334001, China. ${ }^{2}$ Biology and Geography Science School, Yili Normal University, Yining 835000, China.

Received: 3 September 2021 Accepted: 27 December 2021

Published online: 21 January 2022

\section{References}

1. Benvenuti S, Macchia M, Miele S. Light, temperature and burial depth effects on Rumex obtussif olius seed germination and emergence. Weed Res. 2001;41:177-86.

2. Camila MG, Emily PW, Karina BP, et al. In vivo and in vitro genotoxicity studies of aqueous extract of Xanthium spinosum. Br J Pharm Sci. 2012;48:3.

3. Carasso V, Hay FR, Probert RJ. Temperature control of seed germination in Fritillaria tubiformis subsp. moggridgei ( Liliaceae) a rare endemic of the South-west Alps. Seed Sci Res. 2011;21:33-8.

4. Chen $\mathrm{H}$, Maun MA. Effects of sand burial depth on seed germination and seedling emergence of Cirsium pitcheri. Plant Ecol. 1999;140:53-60.

5. Du ZZ, Xu WB, Yan P, et al. Three newly recorded alien invasive plants of Xanthium in Xinjiang. Xinjiang Agric Sci. 2012;49:879-86.

6. Guo CR, Wang ZL, Lu JQ. Seed germination and seedling development of Prunus armeniaca under different burial depths in soil. J For Res. 2010;21:492-6.

7. Hao Q, Zhao HL, Zhou RL. Effects of sand burial on dune plants: a review. Sci Cold Arid Regions. 2014;6:201-8.

8. Li QY, Zhao WZ, Fang HY. Effects of sand burial depth and seed mass on seedling emergence and growth of Nitraria sphaerocarpa. Plant Ecol. 2006;185:191-8.

9. Lin B, Zhao Y, Han P, et al. Anti-arthritic activity of Xanthium strumarium L. extract on complete Freund's adjuvant induced arthritis in rats. J Ethnopharmacol. 2014;155:248-55.

10. Luisa MM, Maun MA. Responses of dune mosses to experimental burial by sand under natural and greenhouse conditions. Plant Ecol. 1999;145:209-19.

11. Maun MA. Adaptations enhancing survival and establishment of seedlings on coastal dune systems. Vegetatio. 1994;111:59-70.

12. Maun MA, Riach S. Morphology of caryopses, seedlings and seedling emergence of the grass Calamovilfa longifolia from various depths in sand. Oecologia. 1981;49:137-42.

13. Ren J, Tao L, Liu XM. Effect of sand burial depth on seed germination and seedling emergence of Calligonum L. species. J Arid Environ. 2002:51:603-11.

14. Seiwa K, Watanabe A, Saitoh T, et al. Effects of burying depth and seed size on seedling establishment of Japanese chestnuts, Castanea crenata. For Ecol Manag. 2002;164:149-56.

15. Soltani A. Seed germination response of Haloxylon persicum (Chenopodiaceae) to different hydrothermal conditions and sand burial depths. Caspian J Environ Sci. 2011;9:211-21.

16. Teixeira LH, Weisser W, Ganade G. Facilitation and sand burial affect plant survival during restoration of a tropical coastal sand dune degraded by tourist cars. Restor Ecol. 2016;24:390-7.

17. Teraminami T, Nakashima A, Ominami M, et al. Effects of sand burial depth on the root system of Salix cheilophila seedlings in Mu Us Sandy Land, Inner Mongolia, China. Landsc Ecol Eng. 2013;9:249-57. 
18. Vander WH, Putten CVD, Peters B. Plant-specific soil-borne diseases contribute to succession in foredune vegetation. Nature. 1993;362:53-6.

19. Vleeshouwers LM. Modelling the effect of temperature, soil penetration resistance, burial depth and seed weight on pre-emergence growth of weeds. Ann Bot. 1997;79:553-63.

20. Wang GH, Yu KL, Gou QQ. Effects of sand burial disturbance on establishment of three desert shrub species in the margin of oasis in northwestern China. Ecol Res. 2019;34:127-35.

21. Wang JF, Gao XM, Dong WG. Survival traits of Crofton weed (Eupatorium adenophorum) seedlings in different habitats. Biodivers Sci. 2008;16:346-52

22. Wang JH, Chai YF, Zhang Y. Effects of sand burial depth of Achnatherum inebrians seed on its germination and seedling growth. Chin J Ecol. 2010;29:324-8.

23. Wang TT, Chu GM, Jiang P, et al. Effects of sand burial and seed size on seed germination, seedling emergence and seedling biomass of Anabasis aphylla. Pak J Bot. 2017:49:391-6.

24. Ye XH, Li LL, Carol C, et al. Sand burial helps regulate timing of seed germination of a dominant herbin an inland dune ecosystem with a semiarid temperate climate. Sci Total Environ. 2019:68:44-5.

25. Yuan ZG, Zheng XW, Zhao Y, et al. Phytotoxic compounds isolated from leaves of the invasive weed Xanthium spinosum. Molecules. 2018;23:2840.

26. Zhang J, Maun MA. Potential for seed bank formation in seven Great Lakes sand dune species. Am J Bot. 1994;81:387-94.

27. Zhao LQ, Zang CX, Yang J. Distribution of a invasive species Xanthium spinosum L. in Inner Mongolia and Ning Xia. Acta Sci Nat Universitatis NeiMongol. 2006;37:308-10.

28. Zheng YR, Xie ZX, Yu Y, et al. Effects of burial in sand and water supply regime on seedling emergence of six species. Am J Bot. 2005;95:1237-45.

29. Zhu YJ, Yang XJ, Baskin CC, et al. Effects of amount and frequency of precipitation and sand burial on seed germination, seedling emergence and survival of the dune grass Leymus secalinus in semiarid China. Plant Soil. 2014;374:399-409.

30. Zuo JC, Liu LD, Kong DR, et al. Effects of sediment burial on seed germination and seedling establishment of Vallisneria natans. J Freshw Ecol. 2016;31:289-97.

\section{Publisher's Note}

Springer Nature remains neutral with regard to jurisdictional claims in published maps and institutional affiliations.

Ready to submit your research? Choose BMC and benefit from:

- fast, convenient online submission

- thorough peer review by experienced researchers in your field

- rapid publication on acceptance

- support for research data, including large and complex data types

- gold Open Access which fosters wider collaboration and increased citations

- maximum visibility for your research: over $100 \mathrm{M}$ website views per year

At BMC, research is always in progress.

Learn more biomedcentral.com/submissions 